\title{
Avaliação de dietas com diferentes fontes protéicas para cães adultos
}

\author{
Aulus Cavalieri Carciofi ${ }^{1}$, Roberto Pontieri ${ }^{2}$, Cristiana Fonseca Ferreira ${ }^{3}$, Flavio Prada ${ }^{4}$ \\ ${ }^{1}$ Departamento de Clínica e Cirurgia Veterinária, Universidade Estadual Paulista, campus de Jaboticabal. Via de Acesso Prof. Paulo Donato \\ Castellane, s/n. Jaboticabal - SP. CEP: 14.884-900. Tel.: (16) 3209-2631. Fax: (16) 3203-1226. \\ 2 Premier Pet. Rodovia SP-215, km 204, Dourado - SP. \\ ${ }^{3}$ Premier Pet. Doutoranda em Medicina Veterinária, Universidade Estadual Paulista, campus de Jaboticabal. \\ 4 Universidade de São Paulo - Faculdade de Medicina Veterinária e Zootecnia.
}

\begin{abstract}
RESUMO - Foram comparados os coeficientes de digestibilidade aparente (CDA) de quatro alimentos secos extrusados para cães, cada um formulado com um dos ingredientes protéicos em estudo: farelo de soja (FS); farelo de glúten de milho (GM); farinha de carne e ossos (FCO); e farinha de vísceras de frango (FV). O experimento foi realizado em delineamento inteiramente casualizado, com quatro tratamentos (ingredientes protéicos) e seis repetições, totalizando 24 animais. As médias dos tratamentos foram comparadas pelo teste Tukey. O CDA da PB (média \pm erro-padrão da média) foi maior na ração à base de GM $(88,13 \pm 0,40 \%)$, seguida pelas dietas com FS $(86,31 \pm 0,34 \%)$, FCO $(85,88 \pm 0,16 \%)$ e FV $(84,84 \pm 0,15 \%)$. O CDA da MS foi maior para a ração com FV $(83,69 \pm 0,09 \%)$, intermediário para GM $(82,41 \pm 0,23 \%)$ e FCO $(82,76 \pm 0,11 \%)$ e menor para FS $(81,10 \pm 0,16 \%)$. As rações à base de proteína animal apresentaram os maiores CDA dos extrativos não-nitrogenados. O teor de MS das fezes dos cães foi elevado na ração com FCO, intermediário naquela com FV e GM e baixo naquela à base de FS. As quatro fontes protéicas estudadas apresentaram bons CDA e, portanto, podem ser utilizadas em rações para cães adultos.
\end{abstract}

Palavras-chave: cão, digestibilidade, proteína

\section{Evaluation of diets with different protein sources for adult dogs}

\begin{abstract}
The coefficient of apparent digestibility (CAD) of four dry extruded dog foods was compared, each one formulated with a different protein source: soybean meal (SM), corn gluten meal (GM), meat and bone meal (MBM) and poultry meal (PM). A completely randomized design was used, with four treatments (protein source) and six repetitions per treatment, in a total of 24 animals. Tukey test was used to compare treatments means. The diet based on GM showed the highest CAD of crude protein $(88.13 \pm 0.40 \%)$, followed by SM $(86.31 \pm 0.34 \%)$, MBM $(85.88 \pm 0.16 \%)$, and PM (83.69 $\pm 0.09 \%)$, with the lowest results. The CAD of dry matter was highest for PM $(83.69 \pm 0.09 \%)$, intermediary for GM $(82.41 \pm 0.23 \%)$ and $\mathrm{MBM}$ $(82.76 \pm 0.11 \%)$, and lowest for SM $(81.10 \pm 0.16 \%)$ The rations based on animal protein presented the highest CAD of nitrogenfree extract. The dogs fecal dry matter was higher for MBM, intermediary for PM and GM, and lower for SM. All the four protein sources analyzed have shown good CAD, and can be used in dog diets.
\end{abstract}

Key Words: digestibility, dog, protein

\section{Introdução}

O mercado de alimentos para animais de estimação no Brasil vem crescendo, em média, 5\% ao ano. Em 2003, a produção nacional de pet food foi de aproximadamente 1 milhão e 300 mil toneladas, o que não atende a $50 \%$ da população estimada de cães e gatos do país (Sindirações, 2004).

Cães exigem altos níveis dietéticos de proteína - mínimo de $18 \%$ para cães adultos e de $22 \%$ para filhotes (AAFCO, 2003). Considerados carnívoros por alguns e como onívoros por outros, muito já se discutiu sobre a superioridade ou não de fontes de proteína animal sobre as de origem vegetal para esta espécie. Na avaliação qualitativa de um ingrediente protéico, são importantes características como: digestibilidade e composição de aminoácidos, que se remetem ao seu valor biológico (Pond et al., 1995); relação proteína:cinzas, larga em ingredientes de origem animal e mais favorável nos de origem vegetal (Cowell et al., 2000); e palatabilidade.

Poucos trabalhos científicos sobre a digestibilidade de ingredientes protéicos para cães puderam ser localizados e nenhum trabalho nacional foi encontrado. Como a origem e o processamento dos ingredientes são fatores determinantes para sua qualidade e digestibilidade (Johnson et al., 1998), a escassez de informações sobre o aproveitamento destas matérias-primas, especialmente as de origem animal, dificulta a formulação de dietas para cães no Brasil, pois os nutricionistas têm acesso apenas a dados de estudos internacionais. 
Neste estudo, avaliou-se a digestibilidade aparente de quatro rações com diferentes fontes de proteína, duas de origem vegetal (farelo de soja [FS] e farelo de glúten de milho [GM]) e duas de origem animal (farinha de carne e ossos [FCO] e farinha de vísceras de frango [FV]) para cães adultos.

\section{Material e Métodos}

Para avaliação das rações com diferentes fontes protéicas, cujas composições químicas encontram-se na Tabela 1, foram extrusadas em uma planta comercial (Premier Pet Dourado - SP) dietas específicas, com quantidades fixas de arroz, milho, polpa de beterraba e suplemento vitamínico-mineral e proporções variadas da fonte protéica em teste, calcário, fosfato bicálcico, amido de milho e óleo de vísceras de frango (Tabela 2).

As rações foram formuladas para apresentar $22 \%$ de $\mathrm{PB}$ (Tabela 3), de modo que, desse total 3,5\% fosse proveniente do arroz, do milho e da polpa de beterraba e $18,5 \%$, da fonte protéica em teste. A composição nutricional das rações experimentais superou as recomendações da AAFCO (2003).

O experimento foi realizado em um delineamento inteiramente casualizado, com quatro tratamentos (ingredientes protéicos) e seis repetições, totalizando 24 unidades experimentais. Foram utilizados cães adultos sadios e desverminados, distribuídos de forma balanceada entre os tratamentos conforme o sexo, o peso e a raça, e mantidos em baias individuais de $4,5 \mathrm{~m}^{2}$. Os grupos de animais foram distribuídos como descrito a seguir:

Grupo 1: três Airdale Terrier, um Collie, um Labrador Retrivier e um Cocker Spaniel Inglês; três machos e três fêmeas; peso do grupo $21,83 \pm 4,67 \mathrm{~kg}$.

Grupo 2: dois Airdale Terrier, um Collie, dois Labrador Retrivier e um Cocker Spaniel Inglês; quatro machos e duas fêmeas; peso do grupo 22,67 $\pm 5,47 \mathrm{~kg}$.

Grupo 3: dois Airdale Terrier, um Collie, um Labrador Retrivier e dois Cocker Spaniel Inglês; três machos e três fêmeas; peso do grupo 20,83 $\pm 5,64 \mathrm{~kg}$.

Grupo 4: dois Airdale Terrier, um Collie, um Labrador Retrivier, dois Cocker Spaniel Inglês; três machos e três fêmeas; peso do grupo $21,67 \pm 6,26 \mathrm{~kg}$.

O experimento teve duração de dez dias, seis de adaptação à ração e quatro de coleta das fezes. $\mathrm{O}$ ensaio de digestibilidade foi conduzido pelo método dos indicadores, segundo recomendações da AAFCO (2003). O alimento extrusado foi moído e misturado com óxido crômico, na proporção de $0,24 \%$. As fezes coletadas de cada animal foram pesadas, homogeneizadas, compondo-se uma única amostra, e secas em estufa, a $65^{\circ} \mathrm{C}$ por 72 horas, para posterior análise laboratorial.

Nas rações extrusadas e nas fezes, foram determinados os teores de MS, CIN, PB, FB e extrato etéreo hidrólise ácida

Tabela 1- Composição química e parâmetros de qualidade das fontes protéicas estudadas, em porcentagem da matéria natural (MN) Table 1 - Chemical composition and quality parameters of the protein ingredients, as-fed basis

\begin{tabular}{|c|c|c|c|c|}
\hline $\begin{array}{l}\text { Nutriente (\%) } \\
\text { Nutrient (\%) }\end{array}$ & $\begin{array}{l}\text { Farelo de soja } \\
\text { Soybean meal }\end{array}$ & $\begin{array}{l}\text { Farelo de glúten de milho } \\
\text { Corn gluten meal }\end{array}$ & $\begin{array}{c}\text { Farinha de carne o ossos } \\
\text { Meat and bone meal }\end{array}$ & $\begin{array}{c}\text { Farinha de vísceras de frango } \\
\text { Poultry by-product meal }\end{array}$ \\
\hline $\begin{array}{l}\text { Umidade } \\
\text { Moisture }\end{array}$ & 12,04 & 8,26 & 6,04 & 2,72 \\
\hline Crude Protein & & & & \\
\hline $\begin{array}{l}\text { Matéria mineral } \\
\text { Ash }\end{array}$ & 5,82 & 1,26 & 26,78 & 12,78 \\
\hline Fibra bruta & 6,44 & 1,72 & & \\
\hline Crude fiber & & & & \\
\hline $\begin{array}{l}\text { Extrativos não-nitrogenados } \\
\text { Nitrogen-free extract }\end{array}$ & 27,22 & 25,51 & 2,28 & 1,07 \\
\hline $\begin{array}{l}\text { Cálcio } \\
\text { Calcium }\end{array}$ & 0,30 & & 9,71 & 3,82 \\
\hline $\begin{array}{l}\text { Digestibilidade em pepsina } \\
\text { Digestibility in pepsin }\end{array}$ & - & - & 80,47 & 81,52 \\
\hline $\begin{array}{l}\text { Solubilidade em KOH } \\
\text { Solubility in } \mathrm{KOH}\end{array}$ & 83,09 & - & - & - \\
\hline $\begin{array}{l}\text { Relação proteína:matéria mineral } \\
\text { Protein:ash ratio }\end{array}$ & 8,08 & 49,28 & 1,93 & 5,22 \\
\hline
\end{tabular}


Tabela 2 - Composição das rações experimentais, em porcentagem da MN

Table 2 - Ingredient composition of the experimental diets, as-fed percentage

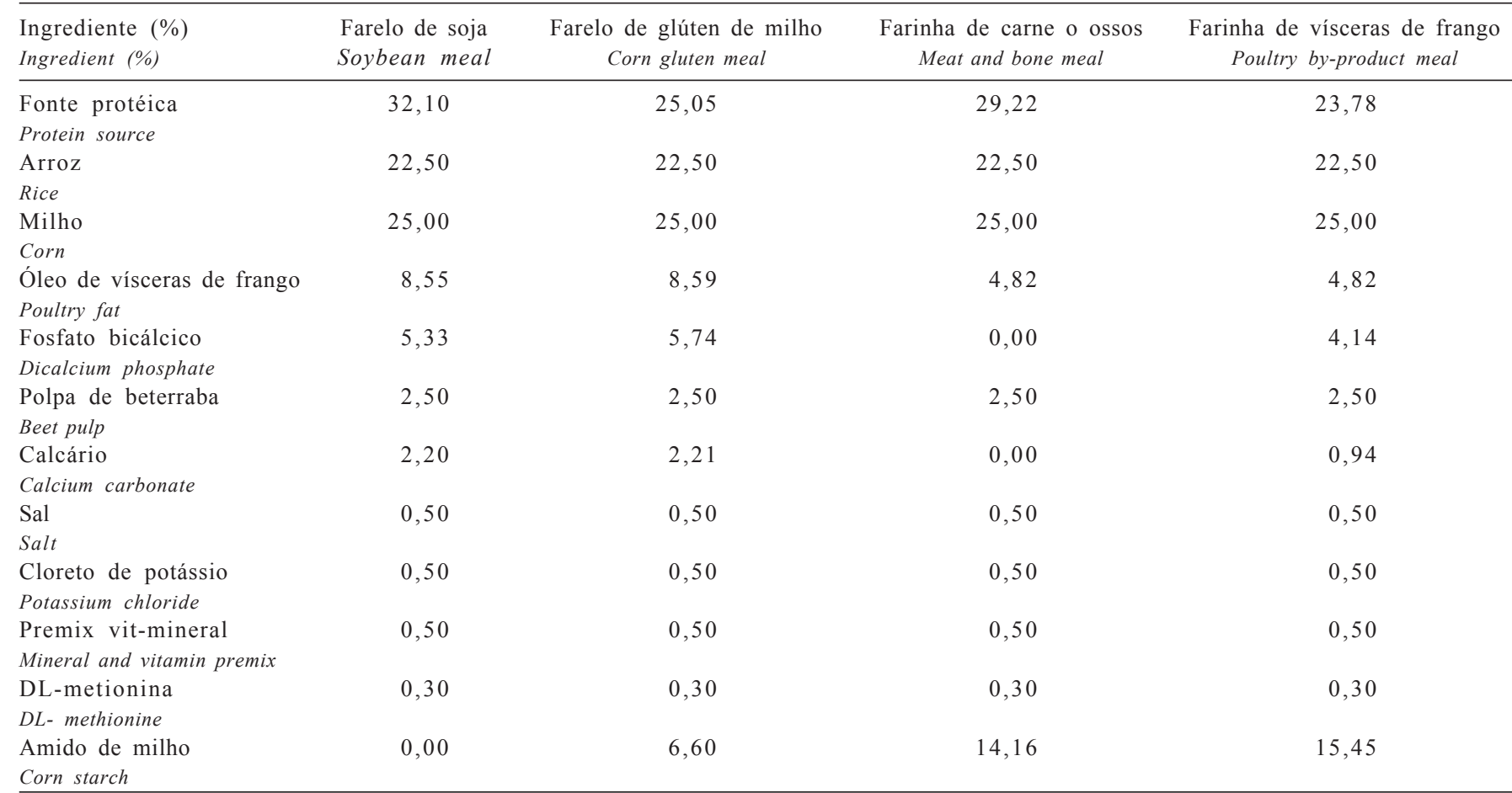

Tabela 3 - Composição química das dietas experimentais ${ }^{1}$, com base na MS

Table 3 - Chemical composition of the experimental diets ${ }^{1}$, dry matter basis

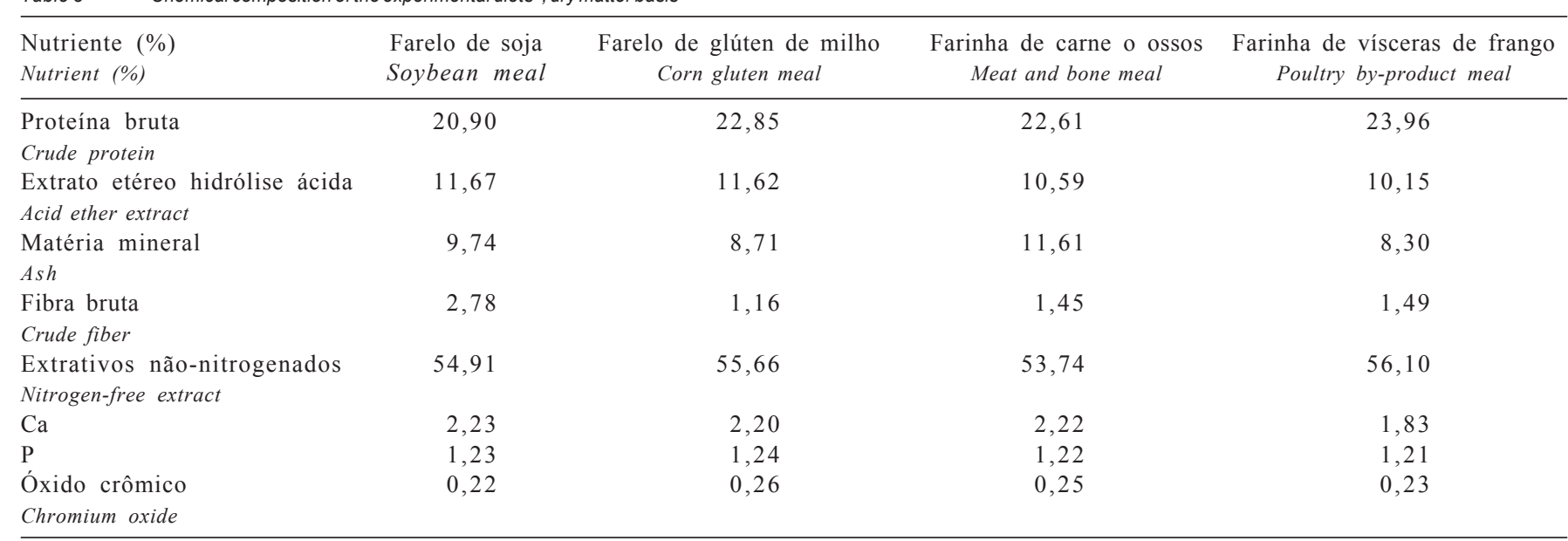

${ }^{1}$ Valores analisados (Analyzed results).

(EEA) e, nos alimentos, determinaram-se, adicionalmente, os níveis de cálcio e fósforo. Os extrativos não-nitrogenados (ENN) foram calculados pela diferença entre a MS e a soma de CIN, FB, PB e EEA. Todas as análises foram conduzidas em duplicata, de acordo com metodologia recomendada pelo Compêndio Brasileiro de Alimentação Animal (1998). O óxido de cromo foi determinado por colorimetria, segundo Fenton \& Fenton (1979).
Os coeficientes de digestibilidade aparente (CDA) dos nutrientes foram calculados de acordo com Andreasi (1956). Os dados obtidos foram analisados utilizando-se o programa estatístico SAS (Schlotzhauer \& Littell, 1997), após as variáveis serem testadas quanto à normalidade do resíduo. Os coeficientes de digestibilidade aparente foram submetidos à análise de variância e as médias comparadas pelo teste Tukey a $5 \%$ de probabilidade. 


\section{Resultados e Discussão}

Os CDA encontrados (Tabela 4) para as quatro rações experimentais foram elevados, indicando bom aproveitamento dos nutrientes, conforme ilustrado na Figura 1.

A ração à base de farelo de soja apresentou o menor CDA da matéria seca, aquelas com farinha de carne e ossos e glúten de milho, valores intermediários, e a com farinha de vísceras de frango, o maior coeficiente $(\mathrm{P}<0,05)$. Desconsiderando-se a interferência da matéria mineral, o coeficiente de digestibilidade aparente da matéria orgânica foi maior para a ração com farinha de carne e ossos e menor para aquela com farelo de soja $(\mathrm{P}<0,05)$.

Não houve diferença estatística significativa entre os CDA do extrato etéreo ácido das quatro rações $(\mathrm{P}=0,57)$. Os CDA dos extrativos não-nitrogenados foram maiores para as rações à base de proteína animal $(\mathrm{P}<0,001)$. As fontes protéicas animais possuem em sua composição muito poucos extrativos não-nitrogenados, mas o farelo de soja apresentou $27,22 \%$ e o glúten de milho $25,51 \%$ desses nutrientes. É possível, portanto, que o menor CDA dos extrativos nãonitrogenados da ração com farelo de soja reflita sua menor digestibilidade em relação ao amido de milho, adicionado em concentração superior a $14 \%$ nas rações à base de proteína animal para fechamento da fórmula (Tabela 2). Os extrativos não-nitrogenados do glúten de milho, no entanto, apresentaram boa digestibilidade, pois o valor encontrado para esta ração foi estatisticamente semelhante ao verificado para a ração com farinha de vísceras de frango.
Estas diferenças nos CDA dos extrativos não-nitrogenados das rações pode explicar os maiores CDA da matéria orgânica e da matéria seca das rações com farinha de vísceras de frango e glúten de milho em relação àquelas com farelo de soja. Wiernusz et al. (1995) estudaram a digestibilidade de vários suplementos protéicos vegetais e constataram que dietas contendo menores teores de oligossacárides, como a proteína isolada de soja e o glúten de milho, possuem maiores coeficientes de digestibilidade aparente e promovem produção de fezes de melhor qualidade. Entretanto, são

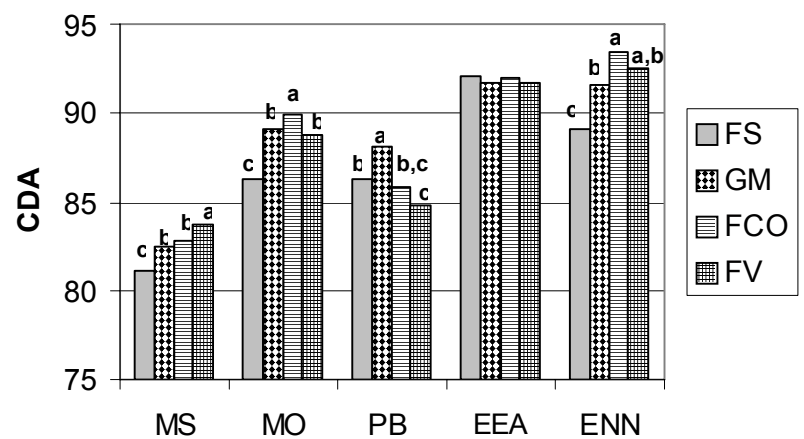

a, b, cMédias de mesmo nutriente sem uma letra em comum são diferentes pelo teste Tukey $(\mathrm{P}<0,05)$. FS - farelo de soja, $\mathrm{GM}$ - glúten de milho, FCO - farinha de carne e ossos, FV - farinha de vísceras de frango. $a, b, c$ Means of the same nutrient without a common letter differ by Tukey test $(P<0.05)$. FS- soybean meal, GM-corn gluten meal, FCO-meat and bone meal, FV-poultry byproductmeal.

Figura 1 - Coeficientes de digestibilidade aparente das rações experimentais.

Figure 1 - Coefficient of apparent digestibility of the experimental diets

Tabela 4 - Coeficientes de digestibilidade aparente e MS fecal de cães alimentados com rações contendo diferentes fontes protéicas (média \pm erro-padrão)

Table 4 - Coefficient of apparent digestibility and fecal dry matter with consumption of diets with different protein sources by dogs (mean \pm standard error of mean)

Farelo de soja Soybean meal
Farelo de glúten de milho Farinha de carne o ossos Farinha de vísceras de frango Corn gluten meal Meat and bone meal

Coeficientes de digestibilidade aparente Coefficient of apparent digestibility

\section{Matéria seca}

Dry matter

Matéria orgânica

Organic matter

Proteína bruta

Crude protein

Extrato etéreo hidrólise ácida

Acid ether extract

Extrativos não-nitrogenados

Nitrogen-free extract

Matéria seca fecal

Fecal dry matter

$82,41 \pm 0,23^{\mathrm{b}}$
$89,16 \pm 0,22^{\mathrm{b}}$
$88,13 \pm 0,40^{\mathrm{a}}$
$91,75 \pm 0,25^{\mathrm{a}}$
$91,60 \pm 0,21^{\mathrm{b}}$
$37,74^{\mathrm{ab}} \pm 1,60$

$81,10 \pm 0,16^{\mathrm{c}}$

$86,33 \pm 0,19^{c}$

$86,31 \pm 0,34^{b}$

$92,07 \pm 0,17^{\mathrm{a}}$

$89,18 \pm 0,36^{\mathrm{c}}$

$30,18^{\mathrm{b}} \pm 1,75$

$37,74^{\mathrm{ab}} \pm 1,60$
$82,76 \pm 0,11^{\mathrm{b}}$

$89,96 \pm 0,11^{\mathrm{a}}$

$85,88 \pm 0,16^{b c}$

$91,90 \pm 0,28^{\mathrm{a}}$

$93,45 \pm 0,13^{\mathrm{a}}$

$41,19^{\mathrm{a}} \pm 2,01$
Poultry by-product meal

a, b, c Médias na mesma linha sem uma letra em comum são diferentes pelo teste Tukey $(P<0,05)$.

$a, b, c$ Means in a row without a common superscript letter are different by Turkey test $(P<0.05)$. 
necessários mais estudos sobre o assunto, pois, em trabalho mais recente, Zuo et al. (1996) não encontraram diferenças na digestibilidade ileal ou total de rações com farelo de soja convencional ou purificado, com baixos níveis de oligossacárides (estaquiose, rafinose e galactinol). Fatores inerentes ao processo de extrusão que influenciam a digestibilidade, como o grau de gelatinização do amido, não foram determinados neste experimento, constituindo-se outra variável importante para os resultados.

As rações compostas de fontes de proteína vegetal apresentaram maiores CDA da proteína bruta, com maior valor para aquela com glúten de milho, seguida pelas rações com farelo de soja, farinha de carne e ossos e farinha de vísceras de frango $(\mathrm{P}<0,05)$. Para facilitar a comparação e discussão dos resultados, na Tabela 5 são descritos os CDA da proteína bruta de diversas dietas experimentais para cães, com diferentes fontes protéicas, encontrados em estudos de digestibilidade - das dietas e não do ingrediente protéico avaliado - na literatura internacional. Os valores encontrados neste estudo corroboram os reportados para dietas à base de farelo de soja, farinha de carne e ossos e farinha de vísceras, embora a variação nos resultados entre os diversos trabalhos seja grande.

Os CDA da proteína bruta das dietas com farinha de carne e ossos e da farinha de vísceras encontrados neste estudo foram próximos aos mais altos valores registrados na literatura, o que permite classificar os ingredientes utilizados como de boa qualidade. A grande diferença de resultados entre experimentos observada para as farinhas de subprodutos de origem animal pode ser explicada pelas variações na composição e no processamento dos ingredientes. A farinha de carne e ossos pode apresentar diferentes proporções de carne, ossos, couro e pêlos, enquanto a de vísceras de frango pode apresentar diferentes proporções de cabeça, pescoço, pés, dorso, intestinos e até a inclusão indevida de penas. O processamento da farinhas animais na graxaria, especificamente a temperatura, a pressão e o tempo empregados, também pode comprometer a qualidade do produto, seja carbonizando matéria orgânica, diminuindo a digestibilidade total, seja tornando aminoácidos específicos indisponíveis. Essas variações têm reflexo direto na qualidade protéica destes ingredientes, podendo ocasionar grandes diferenças entre batidas e principalmente entre fornecedores destes subprodutos (Parsons et al.,1997; Shirley \& Parsons, 2000; Johnson et al., 1998).

Johnson et al. (1998) estudaram a digestibilidade de aminoácidos da farinha de carne e ossos processada em alta $\left(145^{\circ} \mathrm{C}\right)$ ou baixa temperatura $\left(110^{\circ} \mathrm{C}\right)$ e encontraram, respectivamente, coeficientes de digestibilidade aparente médios de 79,2 e 86,4\% para os aminoácidos essenciais e de 75,2 e $84 \%$ para aminoácidos totais, demonstrando a grande influência do processamento sobre a digestibilidade.

Neste estudo, o coeficiente de digestibilidade aparente da PB da dieta com farelo de soja foi inferior ao reportado por Murray et al. (1997) e superior ao descrito por Zuo et al. (1996). Da mesma forma que para as farinhas de subprodutos animais, foi encontrada na literatura grande variação entre experimentos quanto à digestibilidade de dietas à base de farelo de soja. Surpreendentemente, a variação registrada para o farelo de soja foi superior à dos subprodutos de origem animal, com CDA da proteína bruta variando de 64,3 a $88,3 \%$ (Tabela 5 ).

Os produtos derivados da soja têm sido utilizados há muitos anos pela indústria de alimentos para cães e gatos. O farelo de soja desengordurado, a farinha de soja e o grão integral são os mais empregados em alimentos secos e a

Tabela 5 - Coeficientes de digestibilidade aparente da PB de dietas extrusadas para cães, contendo diferentes fontes de proteína, em diversos estudos

Table 5 - Coefficients of apparent digestibility of crude protein of extruded diets for dogs, with different main protein sources, found in different studies

Principal fonte protéica do alimento extrusado

Main protein source on the extruded food

\begin{tabular}{lcccc}
$\begin{array}{l}\text { Autor } \\
\text { Author }\end{array}$ & $\begin{array}{c}\text { Farelo de soja } \\
\text { Soybean meal }\end{array}$ & $\begin{array}{c}\text { Farelo de glúten de milho } \\
\text { Corn gluten meal }\end{array}$ & $\begin{array}{c}\text { Farinha de carne o ossos } \\
\text { Meat and bone meal }\end{array}$ & $\begin{array}{c}\text { Farinha de vísceras de frango } \\
\text { Poultry by-product meal }\end{array}$ \\
\hline $\begin{array}{l}\text { Presente estudo } \\
\text { This study }\end{array}$ & $86,31 \%$ & $88,13 \%$ & $85,88 \%$ & $84,84 \%$ \\
Yanka et al., 2003a & - & - & - & 81,0 a $86,6 \%$ \\
Yanka et al., 2003b & 64,3 a $68,6 \%$ & - & - & - \\
Clapper et al., 2001 & $83,9 \%$ & - & - & $76,9 \%$ \\
Jonson et al., 1998 & - & - & 89,7 a $85,2 \%$ & 80,1 a $82,3 \%$ \\
Murray et al., 1997 & $88,3 \%$ & - & - & $89,5 \%$ \\
Zuo et al., 1996 & 80,3 a $84,6 \%$ & $74,2 \%$ & - & $77,2 \%$ \\
Case \& Czarnecki-Maulden, 1990 & - & & 8,5 & $65,9 \%$ \\
Diferença entre extremos & 24,0 & & 12,3 \\
Difference among extremes & & &
\end{tabular}


proteína texturizada de soja, o mais utilizado em alimentos úmidos (Case et al., 2000). O farelo de soja possui inúmeros fatores antinutricionais, muitos dos quais são termolábeis, como os inibidores de tripsina e quimiotripsina. O subprocessamento da soja mantém estes fatores ativos, prejudicando a obtenção de bons resultados com o alimento (Butulo, 2000). Desta forma, o baixo CDA da PB do farelo de soja encontrado por Yanka et al. (2003), entre 64,3 e 68,6\%, em comparação ao deste e de outros estudos (Clapper et al., 2001; Murray et al., 1997; Zuo et al., 1996), pode ser decorrente do uso de um ingrediente mal processado. Segundo Yanka et al. (2003), a baixa digestibilidade registrada em seu experimento pode ser resultado do alto teor de estaquiose no farelo de soja utilizado (112 g de estaquiose por quilograma de farelo de soja). Entretanto, Zuo et al. (1996) não encontraram diferenças significativas ao estudarem a digestibilidade do farelo de soja convencional e do farelo de soja com baixos teores de oligossacarídeos.

$\mathrm{Na}$ Tabela 5 são demonstrados os resultados de digestibilidade reportados por Murray et al. (1997), os quais são significativamente superiores aos dos demais estudos e os desta pesquisa. A dieta experimental utilizada por aqueles autores incluiu mais de $15 \%$ de ovo em pó, de modo que boa parte da proteína da ração fosse proveniente do ovo e não do ingrediente em teste, o que pode ter promovido resultados artificalmente elevados, e não representativos.

Embora o glúten de milho seja constantemente listado como ingrediente nos rótulos de alimentos para animais de estimação, apenas no trabalho de Case \& Czarnecki-Maulden (1990) constam dados de digestibilidade de dieta à base deste ingrediente. Deve-se considerar, no entanto, que os alimentos utilizados em seu estudo eram à base de glúten de milho ou farinha de vísceras, mas apresentavam significativa proporção de farinha de carne e ossos e farelo de soja em sua composição, o que dificulta a comparação direta entre estes resultados e os descritos por esses autores. Alguns autores consideram o glúten de milho uma fonte de proteína relativamente constante em qualidade, mas com digestibilidade não tão alta quanto à de fontes de proteína animal (Case et al., 2000). Nesta pesquisa, a ração com glúten de milho apresentou o maior CDA da proteína bruta, com valor próximo ao máximo encontrado na literatura para subprodutos de origem animal (89,5\%; Murray et al., 1997).

A consistência e qualidade das fezes se correlacionam à quantidade de água; quanto mais água possuem, mais moles e mal formadas se tornam. Fezes com teor de água muito baixo, por outro lado, podem predispor à retenção fecal e a distúrbios digestivos. Houve diferença estatística entre os teores de água, ou matéria seca, das fezes dos cães
( $\mathrm{P}<0,001)$, (Tabela 4). A farinha de carne e ossos resultou em fezes com menor teor de água, provavelmente em decorrência do alto CDA da matéria orgânica e do maior teor de cinzas deste ingrediente. As rações com glúten de milho e farinha de vísceras de frango resultaram em fezes com teor de umidade intermediário e aquela com farelo de soja, em fezes com maior teor de água, em razão de seu menor CDA da matéria orgânica e dos extrativos não-nitrogenados. A adição de farelo de soja também aumentou o teor de água das fezes dos cães no experimento de Zuo et al. (1996). O farelo de soja é uma fonte de proteína vegetal rica em polissacárides não-amiláceos (Zuo et al., 1996) e, provavelmente, a menor digestibilidade dos extrativos nãonitrogenados e a maior retenção de água nas fezes estejam relacionadas à fermentação intestinal destes compostos no intestino dos cães.

O baixo teor de umidade das fezes dos cães alimentados com a ração contendo farinha de carne e ossos deve-se, em parte, à sua baixa relação proteína bruta:cinzas, um bom indicativo da eficiência da matéria-prima em fornecer proteína sem elevar o teor de CIN da ração, importante na formulação de alimentos secos para cães (Cowell et al., 2000). Ingredientes com excesso de CIN, quando de origem animal, resultam em alimentos com excesso de cálcio, fósforo e magnésio, ou de sílica, quando de origem vegetal, e, portanto, não são compatíveis com a nutrição ótima do animal. Neste aspecto, o glúten de milho e o farelo de soja são ingredientes melhores, a farinha de vísceras de frango, um ingrediente intermediário, e a farinha de carne e ossos, a fonte protéica com maior limitação para inclusão em rações para cães.

\section{Conclusões}

As quatro fontes protéicas avaliadas são adequadas para uso na alimentação de cães. As rações comparadas neste trabalho apresentaram, no entanto, diferenças quanto à digestibilidade aparente dos nutrientes e à qualidade das fezes produzidas pelos cães.

\section{Literatura Citada}

ASSOCIATION OF AMERICAN FEED CONTROL OFFICIAL. Official Publication 2003, Association of American Feed Control Official, 2003.

ANDREASI, F. Estudos de métodos indiretos (óxido crômico e lignina) para a determinação da digestibilidade aparente no cão. São Paulo: Faculdade de Medicina Veterinária e Zootecnia, 1956, 60p. Tese (Livre Docência) - Universidade de São Paulo, 1956.

COMPÊNDIO BRASILEIRO DE ALIMENTAÇÃO ANIMAL. Métodos analíticos. Brasília, Ministério da Agricultura e do Abastecimento, 1998. p.1-199. 
BUTULO, J.E. Qualidade de ingredientes na alimentação animal. Campinas: Colégio Brasileiro de Alimentação Animal, 2002. 430p.

CASE,L.P.; CZARNECKI-MAULDEN, G.L. Protein requirements of growing pups fed practical dry-type diets containing mixedprotein sources. American Journal of Veterinary Research, v.51, n.5, p.808-812, 1990.

CASE,L.P.; CAREY, D.P.; HIRAKAWA,D.A. et al. Canine and feline nutrition. A resource for companion animal professionals. 2.ed. St. Loius: Mosby, 2000. 592p.

COWELL, C.S.; STOUT, N.P.; BRINKMANN, M.F. et al. Making commercial pet foods. In: HAND, M.S.; THATCHER, C.D.; REMILLARD, R.L. et al. (Eds.). Small animal clinical nutrition. 4.ed. Kansas: Mark Morris Institute, 2000. p.127-146.

CLAPPER, G.M.; GRIESHOP, C.M.; MERCHEN, N.R. et al. Ileal and total tract nutrient digestibilities and fecal characteristics of dogs as affect by soybean protein inclusion in dry, extruded diets. Journal of Animal Science, v.79, p.1523-1532, 2001.

FENTON,T.W.; FENTON, M. An improved procedure for the determination of chromic oxide in feed and feces. Canadian Journal of Animal Science, v.59, n.3, p.631-634, 1979.

JOHNSON, M.L.; PARSON, C.M.; FEHEY JR., G.C. et al. Effects of species raw material source, ash content, and processing temperature on amino acid digestibility of animal by-product meals by cecectomized roosters and ilealy cannulated dogs. Journal of Animal Science, v.76, n.4, p.1112-1122, 1998.

PARSONS, C.M.; CASTANON, F.; HAN, Y. Protein and amino acid quality of meal and bone meal. Poultry Science, v.76, p.361$368,1997$.
POND, W.G.; CHURCH , D.C.; POND, K.R. Basic animal nutrition and feeding. 4.ed. New York: John Wiley, 1995 $615 \mathrm{p}$.

MURRAY, S.M.; PATIL, A.R.; FAHEY JR., G.C. et al. Raw and rendered animal by-products as ingredients in dog diets. Journal Animal Science, v.79, n.9, p.2497-2505, 1997.

SCHOLOTZHAUER, S.; LITTELL, R.C. SAS syatem for elementary statistical analyses. 2. ed. Cary: Sas Institute, 1997. 456p.

SHIRLEY, R.B.; PARSONS, C.M. Effect of pressure processing on amino acids digestibility of meat and bone meal for poultry. Poultry Science, v.79, p.1775-1781, 2000

SINDIRAÇÕES. 2004. Acessível em: http://www.sindiracoes.org.br Acesso em: 15/07/04

YANKA, R.M.; JAMIKORN, U.; TRUE, A.D. et al. Evaluation of low-ash poultry meal as a protein source in canine foods. Journal of Animal Science, v.81, n.9, p.2279-2284, 2003a.

YANKA, R.M.; JAMIKORN, U.; TRUE, A.D. et al Evaluation of soybean meal as a protein source in canine foods. Animal Feed Science and Thecnology, v.109, p.121-132, 2003 b.

ZUO,Y.; FEHEY JR., G.C; MERCHEN, N.R. et al. Digestion responses to low oligosaccharide soybean meal by illealycannulated dogs. Journal of Animal Science, v.7, p.2441$2449,1996$. 